\title{
A Personal and Fragile Affair: \\ the sonic environment and its place in my compositions
}

by Thomas Voyce, October 2009

A thesis submitted to the New Zealand School of Music in the fulfillment of the

requirement for the degree of Master of Music in Composition

2009 


\section{Contents:}

Introduction

Page 4

Overview

Page 9

My Practice

Page 10

Listening

Page 11

Recording

Page 12

Playback

Page 14

Transformation

Page 15

Presentation

Page 17

Questions

Page 19

Recording and Reproduction

Page 20

The Art of Noises

Page 23

Musique Concrète

Page 31

Almost Nothing

Page 42

The World Soundscape Project

Page 46

Soundscape as Composition

Page 52

Soundscape Composition

Page 59

Soundscape Composition Versus Musique Concrète? Page 62 


\section{Contents (continued)}

$\begin{array}{ll}\text { Tensions } & \text { Page } 65\end{array}$

$\begin{array}{ll}\text { The Composer } & \text { Page } 66\end{array}$

$\begin{array}{ll}\text { Listening } & \text { Page } 72\end{array}$

$\begin{array}{lr}\text { Indicative Relationships } & \text { Page } 78\end{array}$

A Personal and Fragile Affair $\quad$ Page 84

$\begin{array}{lr}\text { Programme Notes } & \text { Page } 92\end{array}$

$\begin{array}{ll}\text { Bibliography } & \text { Page } 97\end{array}$ 


\author{
A Personal and Fragile Affair: \\ the sonic environment and its place in my compositions \\ by Thomas Voyce, October 2009
}

\title{
Introduction
}

In 1999, while studying composition at the Victoria University School of Music in Wellington, I was working part-time as a security guard at the Wellington International Airport. The airport had not yet opened, and while there was electricity to most of the building, the main electronic doors were not powered, wide open and posing a security risk at night. I was positioned there for about a week, working alone from 9 at night until 6 in the morning. I would get a few hours sleep before attending classes, and then repeat the process. The experience was at times surreal; the building was big and empty, fluorescent tubes lit every inch of it; muzak versions of popular classical tunes and Beatles songs permeated every space, repeating over and over again, night after night, through hundreds of speakers in the ceiling; 737's would come and go at the beginning and end of my shift, with the final flight out of Melbourne landing somewhere in between.

I was taking a second-year electro-acoustic composition paper with Dr. John Young at the time, and I decided to use the sounds of the airport as the source material for my final major composition. The decision was made partly because I had no spare time to record elsewhere, but also because as the week progressed, I 
had built a strange affinity with the place and developed a keen understanding of the sonic environment. I made my recordings in one evening, using a matched pair of AKG 451's and a portable DAT recorder. Unfortunately, the recorder had run out of batteries as the then Prime Minister Helen Clark walked through the doors (now powered) flanked by security, airport officials and Maori dignitaries. I was an uninvited guest at the official pōwhiri. It was a fitting end to a bizarre week.

I clearly remember playing my piece to Dr. Young and my classmates a few weeks later. For the most part, the 7 minute work focused on the sounds of engines starting up, shutting down, planes taxiing to and from the runway, and all the beeps and sirens associated with such activity. The material was largely unprocessed, save some subtle filtering, and the piece progressed from one noise band to another, with a section in the middle dedicated to a convoluted reinterpretation of Edelweiss, a particularly bad muzak version I had heard perhaps 10 times a night during my posting. I remember being happy with my piece. It represented the sounds I was hearing, and encapsulated my experiences (and somewhat distorted emotional state). Dr. Young had a different opinion. He felt the inclusion of the Edelweiss recordings was a poor decision; it had no relevance to the rest of the material, it wasn't processed enough, its primarily pitched content failed to integrate with the noise content of the engines. It became clear to me in an instant that working with largely unprocessed field recordings as a source for composition posed a whole matrix of issues. I was being criticised for not 'listening' to my work, whereas I felt the whole experience had been a profound exercise in 
listening. I wondered how he would have felt if I had included the pōwhiri I had failed to capture. The problem was further compounded when, years later, I replayed the piece, and couldn't help but agree with Dr. Young's initial critique.

In the same class, we listened to Katherine Norman's Hard Cash (and small dreams of change), ${ }^{1}$ and were asked what we thought of it. The piece includes field recordings made at Brighton Pier and interviews with people around London. A heated discussion took place regarding the use of the human voice in acousmatic music. Some could not escape the arresting nature of the human voice, the content of the words, and the way the voices (and their messages) took precedence over everything else. Others argued that the human voice should be treated as merely another sound in the mix. They felt the fairground recordings were equally imposing and the composer's 'message' was open to interpretation or could be disregarded altogether. I myself left the class feeling confused about the music. It was documentary on one level, but not exclusively so. The material was at times referential and arresting, and at others heavily processed and ambiguous, encouraging a more reduced mode of listening. I enjoyed the piece because it resulted in a number of responses: recognition, uncertainty, technical appreciation, and empathy.

These experiences in my electro-acoustic composition class highlighted many concerns regarding the use of field recordings in acousmatic music. I left university

1 Katherine Norman, 'Hard Cash (and small dreams of change)', in Sonic Circuits V, American Composers' Forum (Innova 114), 1999. 
with these concerns unresolved, but continued to record sound environments, mainly because of the enjoyment I received from the process of recording, but also because of the sense of wonder these sounds gave me on playback. I didn't build any pieces out of these recordings until 2005 when I began an Honours degree at the New Zealand School of Music.

One of my Honours pieces included recordings I had made in Japan, melded with improvisations made on traditional instruments, and improvisations in the studio with analog equipment. The piece was successful in my opinion, and spurred me to begin a Master of Music degree, utilising sounds I would gather on a month-long voyage around the Caribbean and the Americas. As part of my MMus, I decided to tackle some of the issues that I had left unanswered 7 years earlier. By this stage, I had heard the term 'soundscape composition', and read R. Murray Schafer's Tuning of the World. While I felt a certain empathy with the concepts raised within acoustic ecology, many of the ideas felt at odds with my own motivations. My experiences with electroacoustic composition and the way referential material was dealt with (often as a material to be processed and 'musicalised') also seemed to be dissonant with my own practice.

At the commencement of my research it appeared to me that the use of referential material in electroacoustic composition was contentious, especially regarding the retention of the source/cause relationship. While I have a clear preference for certain sound environments and the way they should be transformed, if at all, I was 
less sure about how my work fitted into this discourse. This would become the focus of my research. 


\section{Overview}

To begin with, I will briefly outline my compositional process. This will help to provide an understanding of my motivations. I will then pose some questions relating to the practice of field recording and the use of these materials in electroacoustic composition. Through a discussion of early electronic music, musique concrète, soundscape composition and the ideologies of composers associated with these movements, I will reveal the tensions surrounding the use of referential material in acousmatic music. Finally, I will show how I have attempted to address these tensions in my own work. 


\section{My Practice}

The concept of listening is central to my compositional processes. It occurs not once or twice, but several times throughout the creation of a piece and beyond. My listening perspective changes repeatedly, as I assume the roles of audience and composer in varying proportions. The route to a finished piece can be mapped out as follows:
1) Listening
2) Recording
3) Playback
4) Transformation
5) Presentation 


\section{Listening}

The listening experience for me is a multi-layered affair. It starts with a fundamental appreciation of a sound environment and this ranges from a purely contextual listening mode (i.e. object centered - as defined by Denis Smalley ${ }^{2}-$ that is listening to the messages encoded in the sounds) to a more abstract listening approach (listening to the spectromorphological properties of the sonic environment). While this is essentially an appreciative form of listening, very seldom do I listen without analysing the sonic environment's potential for mediation. The more I compose with environmental recordings, the more complex this initial listening experience becomes. In essence, my listening experience informs my compositional process, and in turn, my compositional process informs my listening experience. The ability to switch between these different types of listening (appreciative, and pre-emptive) involves a very conscious change in focus.

2 Denis Smalley 'The Listening Imagination: Listening in the Electroacoustic Era', Contemporary Music Review, Vol. 13, Part 2, 1996, pp. 78 


\section{Recording}

Capturing the sonic environment is the next part of the process. This is a technical exercise, and it involves an entirely new listening experience. As part of my recording process, I have decided to restrict my recording techniques and equipment in order to create a cohesive technical substrate for my work. I believe it does not take an expert listener to distinguish between a recording made by a tape recorder and a digital one, or with a different microphones in different configurations. Though an individual may not be able to articulate the difference, the brain is aware of these subtleties in colour and imaging. I restrict such colouration by using a matched pair of $\mathrm{AKG}$ C451B microphones, recorded through Sound Devices pre-amps, A/D converters, in 24bit at 96khz, with occasional limiting. This results in a very uniform raw material. By comparison, a camera lens with a $21-35 \mathrm{~mm}$ focal length, capturing images at 24.6 mega pixels will provide a certain grain and perspective to the photographs (there are many similarities between photography and field recording, which I will touch on later).

Having worked with a variety of microphones and recorders in many different settings, I would say that the equipment I have used to make these recordings, though convenient, is not my preferred configuration. The C451B microphones, while small in size and easy to handle, are very coloured, with limited lower frequency response. The Sound Devices pre-amps, while quiet, are not as quiet as 
some pre-amps I have used in studio environments. When using digital recorders, the quality of microphone pre-amps becomes of greater concern to me. Many of the more desirable recorders (such as Nagra tape machines) are prohibitively expensive. Larger-diaphragm condenser microphones, capable of capturing a greater range of frequencies, are less suited to the outdoors without serious protection from wind and condensation. In my experience, the initial collection (and colouration) of raw material has a greater impact on the final 'tone' of recorded sound than any subsequent filtering or other manipulation. While I would prefer the sound of large-diaphragm microphones and an analogue tape machine, I have settled for the technology available to me for this project.

In terms of the microphone formation, I have used the C451B microphones in the same near-coincidental configuration (ORTF) for each recording. This allows for a wide stereo image that is fairly sharp and realistic (the capsules are ear-distant apart minus the baffling of the head). For this project, I have recorded environments that humans are likely to hear if they were in the same spot (at head-height). The reason for using an ORTF configuration at head height is to recreate a realistic listening experience, where objects in a sound field interact in a way that is familiar to a listener. By contrast, I could have recorded environments at ground level with boundary microphones, or at 20 meters with a single shotgun microphone. These techniques (including hydrophonic recording and ambisonic recording) I wish to explore in future projects. 


\section{Playback}

Much of the listening process in the initial identification and collection of material is made with playback firmly in mind. While documentation has a degree of dislocation from the environment (via headphones and microphones), in the studio the sonic environment is totally decontextualised, and it becomes an acousmatic event. This process is always revealing. Sometimes, a recording meant for manipulation is better used as a phonographic document. Other times the opposite is true. It is only at this point that such distinctions can be made. It is a process of re-evaluation, and listening with fresh ears. For some artists, this is where the process ends. The question of whether these recordings as experienced through loudspeakers (phonography) can be regarded as art is a subject of debate, which I will discuss later.

During this initial playback stage, I imagine how further transformations might sound. Pitch-shifting, filtering, editing, delay and modulation effects are some of the methods used, and the more I work with sound, the better I am able to foresee potential outcomes. As mentioned, I often consider the potential of environmental sounds for manipulation before they are recorded. At playback, an environment at first considered suitable for pitch shifting, may seem better suited to band-pass filtering, though it is not until the next compositional stage (transformation) where these potential manipulations can be experienced in a real way. 


\section{Transformation}

There are a variety of ways in which recordings are transformed for use in compositions. To begin with, materials need to be selected to work with. This selection process happens in one of two ways. Firstly, I will be working on a piece where the subject matter is already decided, and the materials will be auditioned accordingly. This is often the case when I am working with materials that were gathered at the same time and place with a view to using these as the basis of a piece. Many of my pieces for this project deal with a kind of recreation of a place or attributes of it. Multiple recordings are either used for the purpose of making related 'scenes' in more referential works, but also for maintaining a sense of sonic cohesion in more abstract works (as outlined in the recording process). The second kind of selection occurs through random audition. This is where recordings from my archives are auditioned, and a single recording is selected. From this point, other materials may be selected for their referential similarities (e.g. elemental sounds, wildlife sounds, industrial sounds etc), or they may be selected for their similar spectromorphological characteristics. Or, materials may be selected for their contrasting referential and/or spectromorphological properties.

The manipulation process depends greatly on the technology used. Some pieces are realised through the use of an outboard mixing console, with outboard effects. In this case, a lot more improvisation takes place, and the technological intervention is 
more pronounced. In other pieces, the processing occurs 'in the box', that is to say, using a computer programme with the plug-ins and effects available there in. The use of the computer allows for larger forms to be observed at a glance, with much more subtle use of volume automation, cross fading, and multiple effect parameter manipulation. Pieces made in this way are often longer and slower evolving, though this is not always the case. In many instances, a mixture of the two processes is used, usually beginning with an outboard manipulation of materials followed by a computer arrangement. The final compositions are never realised at the mixing console. The outboard equipment is used to generate material in a spontaneous and performed fashion, while the rendering of materials to completion is done in a more exacting and premeditative manner. Attention to detail is important, and the computer software I use (Protools) has superior capabilities in this area. The way in which the materials are manipulated and arranged depends greatly on the materials themselves. This is an area I will discuss later with regard to specific works. 


\section{Presentation}

As with the uniform capturing of materials described in the section entitled 'recording' above, I have also decided to limit the presentation of the compositions to stereo reproduction through full range monitors. Where frequencies below $50 \mathrm{hz}$ are poorly represented, sub-woofer reinforcement should be used. Again, this is to create a cohesive body of work that can be replayed in a single format. These works are very much designed for reproduction. As this 2-channel format suggests, there is a direct connection between the way the materials are captured and how they are presented. Stereo imaging is fundamental to my compositions, and as much as possible I like to preserve the original imaging of the recordings. This ties back to the way in which materials are transformed. I seldom use reverberation effects to give a new sense of space. I prefer the use of filtering and pitch shifting to process the materials. This ensures that the original sense of space and interplay between sounding objects is maintained, even when transposed. I am very much aware that the potential to explore multi-channel works and sound installation is enormous. Multi microphone recordings (such as ambisonic and 5.1 arrays), is something that I am greatly interested in, especially as my work often focuses on

preserving and recreating 'natural' spatial interplay. These are areas I look forward to exploring in future projects. For the purposes of this project, these compositions appear as stereo interleaved .wav files, dithered to $16 \mathrm{bit}, 44.1 \mathrm{khz}$ on compact disk, though the original 24 bit, $96 \mathrm{khz}$ versions are archived. 
Looking carefully at my compositional processes and listening to the works, it is clear to see preferences for certain materials and ways of working. The majority of materials have vivid spatial characteristics and fairly balanced object interplay (that is, dominant foreground activity is passed over in favour of environments where the listener is encouraged to explore the content in a less directed fashion). Less recognisable sound environments are favoured over clearly perceptible ones, with the latter being subjected to heavier transformation when used. It would appear that on the one hand, the integrity of the sonic environment is very important to my work, especially regarding the perception of space. On the other hand, the identity of objects within the sound environment is usually rendered ambiguous (or environments are recorded because of their un-mediated ambiguity). In the case of phonographic works, I have a tendency to present materials that have a high degree of referentiality, with many of these recordings containing aspects of human activity.

As I found early on in my undergraduate electroacoustic composition class, the more ambiguous a sound is, the more it can be heard for its intrinsic qualities, and the easier it can be appreciated in the context of electroacoustic composition. This preference for decontextualised sound seems deeply ingrained in the genre (as I will explore later), and though some of my compositions use heavily processed materials some of the time, it is not the primary focus of my work. 


\section{Questions}

Some of the concerns I have encountered through the course of this project, both my own concerns and those raised by others, are focused primarily on the use of referential material in acousmatic music. On a basic level, can a recording (that is to say, a phonographic work) be regarded as 'music?' Why is this a question to begin with? How have the ideologies of musique concrète and soundscape composition contributed to the discourse surrounding acousmatic music with extended environmental material? How should this music be listened to? If it is created within the context of electroacoustic music, should it be decoded in a manner suitable to the genre? If the experience is focused more on the integrity of the materials themselves, is 'soundscape composition' a better format within which to experience the works?

It is important to note that many of these questions result from the advent of recording and playback technologies themselves. It is to this technology which I will now turn. 


\section{Recording and Reproduction}

The possible invention and influence of recording technology had been contemplated many times before its existence. Athanasius Kircher, a Jesuit Scholar of worldwide repute, described the recording and playback concept in his Phonurgia Nova of 1673; 'The secret quomodo omnis generis instrumentorum Musica in remotissima spacia propagari possit (whereby all forms of instrumental music could be transmitted to remote places) was a special preoccupation...' (Schafer 1977: 90).

Sir Francis Bacon, writing almost 50 years earlier of 'sound-houses' in his fictional work New Atlantis, describes how the inhabitants of Bensalem 'have all means to convey sounds in trunks and pipes, in strange lines and distances'. (Bacon 1624)

In the mid $19^{\text {th }}$ century, progress was being made towards the reproduction of sound, culminating in Leon Scott's Phonoautograph in 1857. A horn was used to channel sound waves to a diaphragm, which was then transduced onto a cylinder via a stylus. This development, along with Alexander Graham Bell's telephone in 1876, would ultimately lead to a realisation of Kircher's dream. Recording, playback and transmission had been born.

The Phonograph went through a series of developments (notably Edison's Phonograph and later the Gramophone), but it was not until the mid 1920's, with 
the use of an electromagnetic cutting head replacing the horn, that the quality of audio reproduction began to increase rapidly. In conjunction with microphones, electromagnetic recordings were louder and clearer than their predecessors. In 1935, AEG launched the K1 tape recorder. Magnetic tape would become the standard medium for recording for the next 50 years.

It is fair to say that acousmatic music was only made possible due to these advances in technology. In turn, the impact of this technology on music has been enormous and well documented. It has brought about huge changes in the way we listen to music, the way we create it, and the way we perceive it. The concept of reproduction and its impact on the world was clearly expressed by Walter Benjamin in 1936 with his paper Das Kunstwerk im Zeitalter Seiner Technischen Reproduzierbarkeit (The Work of Art in the Age of Mechanical Reproduction). In it he wrote:

For the first time in world history, mechanical reproduction emancipates the work of art from its parasitical dependence on ritual. To an ever greater degree the work of art reproduced becomes the work of art designed for reproducibility. (Benjamin 1936)

This observation articulates the impact recording and playback technology was having as it spread across Europe and America. 
Recording technology would realise Kircher's dream, and it would also realise the dreams of those wishing to capture the sounds of our environments; "evanescence and recollection... has become tangible and manifest through the gramophone recording" (Adorno 1927). The connection between recording technology and the ability to create completely new art (as opposed to simply documenting musical ensembles), would not be made until the 1920s. Unsurprisingly, radio engineers, people with direct access to the technology, would be among the first to create this new art. Also with a degree of predictability, composers from the Western art music tradition would embrace the new technology for making music, as the desire for a new medium for composition was growing. Perhaps the strongest call for something new would emanate from Milan shortly before the commencement of the First World War. 


\section{The Art of Noises}

Luigi Russolo, a composer, painter and ardent Futurist, expressed his desires in what has come to be considered by many composers as the founding treatise for acousmatic composition and perhaps also soundscape studies, The Art of Noises (1913). Written many years before the first acousmatic pieces were realised, Russolo documents his appreciation of the sonic environment (especially modern industrial sounds), his desire to incorporate them into music, and his general dissatisfaction with the materials of contemporary composition. Russolo's ears were listening attentively to the world around him, and while he wrote, music of the future played in his head.

To begin his treatise, Russolo outlines, somewhat skeptically, the development of Western art music from 'ancient life' until the present day:

Ancient life was all silence. In the nineteenth century, with the invention of the machine, Noise was born. Today, Noise triumphs and reigns supreme over the sensibility of men. For many centuries life went by in silence, or at most in muted tones. The strongest noises which interrupted this silence were not intense or prolonged or varied. If we overlook such exceptional movements as earthquakes, hurricanes, storms, avalanches and waterfalls, nature is silent. (Russolo, 1913) 
This paragraph, the first in his historical overview, highlights a certain preoccupation of the futurists with the sounds of industry. Famously, Russolo implores us to 'cross a great modern capital with our ears more alert than our eyes.' Had he arrived at the shores of New Zealand as a naturalist, not Futurist, he may have had a very different view of the pre-industrial world:

This morn I was awakd by the singing of the birds ashore from whence we are distant not a quarter mile, the numbers of them were certainly very great who seemd to strain their throats with emulation. (Joseph Banks in King, 2003: 15)

It was noted that this dawn chorus as experienced by Banks, would have been a 'mere echo of what could have been heard 400 years before.' ${ }^{3}$ Presumably, without the hinderance of human enterprise, twelfth-century New Zealand would have been deafening through the cumulative sounds of her wildlife.

It is highly likely that Russolo was unaware that 'ancient life' was perhaps louder than Milan in 1913. It is also possible that his appraisal of the pre-industrial world was informed by his experience of non-industrial environments, such as the countryside, where the impact of human activity had driven out most of the natural noisemakers. It is notable that animals are conspicuously absent from his list of

3 King, Michael. The Penguin History of New Zealand. Auckland: Penguin Books (NZ), 2003. pp. 15 
'exceptional' noisy, natural events. These issues would eventually be touched on by the acoustic ecologists at Simon Fraser University, but not for another 50 years.

This is not to say that Russolo didn't appreciate the sounds of the natural world. He draws almost exclusively on natural phenomena (the sounds of thunder, wind, and water) in order to 'convince ourselves of the amazing variety of noise.' Natural sounds are also included in his 6 families of noises of the Futurist orchestra, not as a category, but as part of wide categorizations that describe, for the most part, sounds and not their origins. It seems that while Russolo had a preference for industrial sounds, he saw natural sounds as having equal potential in his vision for the future.

Russolo makes an interesting comparison between the developments of industry with the development of harmony. He suggests that listeners in the eighteenthcentury would not have appreciated the harmonic complexity of early twentiethcentury orchestral music, as appreciation of such sounds requires a listener to be educated by 'modern life'. While this may or may not be true, it is fair to point out that the level of industrial noise would have been at an all time high in the early twentieth-century, as would have the level of dissonance in contemporary music, perhaps only to be surpassed by the noise of the Second World War and the music made in its aftermath. War and the sounds of warfare were of particular interest to Marinetti, the central figure of the Futurist movement. Of contemporary harmonic complexity, Russolo wrote 'our ears are not satisfied merely with this, and demand 
an abundance of acoustic emotions.' In essence, Russolo was searching for the next level of integration between noise and music that contemporary music wasn't providing.

Russolo's dissatisfaction with Western art music was shared by his teacher, Ferruccio Busoni. A composer and writer, Busoni penned the Sketch of a New Esthetic of Music two years prior to Russolo's treatise. Busoni believed that other art forms, such as architecture, poetry and sculpture, were 'mature' arts. He wrote: 'music, compared with them, is a child that has learned to walk, but must still be led.' (Busoni 1911)

Busoni believed that music (a 'virgin' art) should be set free from the restrictions of the Western tradition. 'We have formulated rules, stated principles, laid down laws; we apply laws made for maturity to a child that knows nothing of responsibility!'

The notion of freeing music from the past was further emphasised in Russolo's Art of Noises, in a dramatic fashion typical of Futurist writers:

Away! Let us break out since we cannot much longer restrain our desire to create finally a new musical reality, with a generous distribution of resonant slaps in the face, discarding violins, pianos, double-basses and plaintive organs. Let us break out! 
Certainly Russolo had a clear idea in his mind of what the new music should sound like. Clearly, in his numbered conclusions found at the end of The Art of Noises, Russolo identifies new instrument construction as the primary way to realise his goals. Russolo set about building instruments that would make these 'new' noises, called intonarumori, essentially resonant boxes with speaker horns, producing a variety of different noises depending on how they were manipulated (usually by hand crank) and which type of vibrating material was used. While the technology existed to realise a music that literally captured the sounds of modern life, the important step from concept to medium wouldn't be made for a number of years, although as Battier recounts, many had conceived of such music during this gap. ${ }^{4}$

A contemporary of Busoni and Russolo, Edgard Varèse, shared a similar passion for new ideas and sounds, and would incorporate new electronic instruments into his compositions, such as the Theremin and the Ondes Martenot. Varèse would eventually tire of these new instruments, and he famously wrote to Leon Theremin in 1941 regarding this: 'I don't want to write any more for the old Man-power instruments and am handicapped by the lack of adequate electrical instruments for which I now conceive my music.' (Varèse in Glinsky, 2000: 323) Varèse would use tape in his later years, realising Déserts at Pierre Schaeffer's studio in Paris.

Varèse, spending much of his life in both Paris and the United States, was a profoundly influential figure to a number of new composers on both sides of the

4 Marc Battier, 'What the GRM brought to music: from music concrete to acousmatic music', Organised Sound. Vol. 12 no. 3, 2007 pp. 189-202 
Atlantic, as was Arnold Schoenberg, who was Busoni's successor as the Director of a Master Class in Composition at the Prussian Academy of Arts in Berlin upon his death in 1924.

Six years after Busoni's death, and twelve years after Russolo's Art of Noise, Walter Ruttmann, an experimental filmmaker and multi-media artist, played his work Wochenende (1930) on German radio. The piece is a collage of sounds, music and words, depicting a weekend in the urban metropolis of Berlin. In 1929, Ruttmann wrote:

Everything audible in the whole world becomes material. This infinite material can now be given new meaning by fashioning it in accordance with the laws of time and space. This opens the way for a completely new acoustic art - new in its means and in its effect. ${ }^{5}$

Ruttmann's words resonate with many of Russolo's ideas. The 'real world' and 'found sound' as material for art is the basic premise for Wochenende, with the piece and its ideology often cited as precursors to musique concrète. Where Russolo had invented new instruments to explore the relationship between the sonic environment and music, Ruttmann had found an entirely new way to explore this realm, utilising new technology not to mimic the real world, but to capture and

5 Ruttmann, Walter. http://www.medienkunstnetz.de/works/weekend-remix/, accessed 8 April 2009 
rearrange it as he saw appropriate. Referential material in extended works had found a home in radio. Radio studios would become breeding grounds for experimentation, new technology and new ideas for many decades to come, with arguably the most influential studios residing in Paris and Cologne.

In America, similar ideas were surfacing. Harry Partch was building new instruments to express his passion for microtonality, and Henry Cowell was experimenting with existing instruments, notably in Aeolian Harp (1923). His piano string manipulations in this work would provide inspiration for John Cage's prepared piano. In 1937, during a lecture in Seattle, Cage expressed his ideas on the future of music. The opening of his lecture focused on the sonic world as a material for 'organized sound'. As with Russolo and Ruttmann, Cage did not discriminate between the sounds of human industry and the sounds of nature. Seemingly both sound worlds had a place in their future of music.

Wherever we are, what we hear is mostly noise. When we ignore it, it disturbs us. When we listen to it, we find it fascinating. The sound of a truck at 50 M.P.H. Static between the stations. Rain. We want to capture and control these sounds, to use them, not as sound effects, but as musical instruments. (Cage, 1937)

In the 1930's, Ruttmann, Benjamin and Cage were all contemplating the future of art with regard to new technology. The yearnings of Busoni and Russolo to break 
from tradition would find a home in this new 'acoustic art'. It seems to me that these individuals, especially Russolo, Ruttmann and Cage, regarded all the elements of our sonic environment with a child-like wonder; the infinite potential of everyday sound in music knowing no limits. In many respects, it is with this same sense of wonder that I approach the world around me and the sounds contained within it. For me, the complexity of the sonic environment is a source of great inspiration, and the latent potential of these sounds to be captured and transformed provides the primary motivation behind my work. In this regard, I identify the likes of Russolo, Ruttmann and Cage as pioneers of my compositional practice.

Although the desire to unleash the potential of everyday sounds in music flourished in the first half of the twentieth-century, the next wave of electronic music composers (notably composers of musique concrète) would quickly deem recognisable sound materials unworthy for composition. It is difficult to say if Russolo would have approved of this development. Was the context of a sound important, or just the potential to use it discretely? Additionally, if Busoni objected to the laws placed on Western art music (' a child that knows nothing of responsibility'), how would he have reacted to to the news laws placed on acousmatic music, a considerably younger child? 


\section{Musique Concrète}

Pierre Schaeffer, working at Radiodiffusion-Télévision Française (RTF), pioneered many techniques in electronic composition that would be used for years to come. He would also assemble a group of composers around him focused on creating this new music. As a result, Schaeffer began a new movement in Western art music.

While working for RTF in the 1930's, Schaeffer experimented with record players, reversing sounds, transposing them, layering them, sillion fermé (looping) and cloche coupée (the exclusion of attack and decay transients). These were techniques that had not been explored until this time. With Etudes aux Chemins de Fer (1948), composed a year after the death of Russolo, Schaeffer had turned the Futurist's dream into prophecy, incorporating sounds from 'the variety of din, from stations, railways, iron foundries, spinning wheels, printing works, electric power stations and underground railways.' (Russolo 1913)

Three years later, in 1951, Schaeffer founded the Groupe de Researche de Musique Concrète (GRMC), building an electroacoustic studio for the purpose of making new music. This was the same year that tape recorders were introduced as the primary tool at RTF, and also the same year Herbert Eimert set up a studio at Westdeutscher Rundfunk (West German Radio) in Cologne. It is important to note that the Cologne studio, while utilising some of the same equipment as the GRMC, 
had a very different approach to composition. Brindle summerises Schaeffer's ideas on this matter succinctly:

[Whereas musique concrète] begins with a prepared sound material, which is molded into its final form by a process of experimentation, trial and error, perhaps following unexpected paths that were never foreseen initially, electronic music [at the Cologne Studios] was composed like traditional music, first being conceived in the mind of the composer, then written down, and finally realised in sound. (Brindle 1987:104 )

As Ruttmann's Wochenende utilised found sound materials, it is easy to see a direct correlation between his work and the composers at RTF twenty years later. In contrast, practices at the studio in Cologne resonate more strongly with traditional Western composition, especially as its director, Dr. Eimert, was a champion of serial music, and his doctorate dealt with seventeenth- and eighteenth-century musical structures. ${ }^{6}$ Unlike the experimentation of musique concrète, Cologne worked with pre-composed forms and pitch structures. The electronic music devices were initially seen more as an extension of existing instrumentation as opposed to a compositional tool as they were in Paris. It is convenient to note at this time that Schaeffer regarded his work as purely experimental, as opposed to

6 Information sourced at http://www.elektropolis.de/ssb_eimert.htm, accessed 12 August 2009 
musical. He would confess to Tim Hodgkinson in 1986 that the experimentations were not rewarding in a musical sense:

Each time I was to experience the disappointment of not arriving at music. I couldn't get to music - what I call music. I think of myself as an explorer struggling to find a way through the far north, but I wasn't finding a way through. ${ }^{7}$

Still, in the pursuit of music through experimentation, Schaeffer would discover some very enduring concepts. L'Objet Sonore, or the sonic object, was fundamental to the development of musique concrète. Schaeffer:

In listening to sonorous objects whose instrumental causes are hidden, we are led to forget the latter and to take an interest in these objects for themselves. The dissociation of seeing and hearing here encourages another way of listening: we listen to the sonorous forms without any aim other than that of hearing them better, in order to be able to describe them through an analysis of the content of our perceptions. (Schaeffer 2006:78)

7 Tim Hodgkinson and Pierre Schaeffer. 'Pierre Schaeffer an interview with the pioneer of musique concrete' http://www.ele-mental.org/ele_ment/said\&did/schaeffer_interview.html, accessed 7 June 2009 
The sonic object and recording/playback technology are inseparable, and hence Schaeffer's concept is truly a revolutionary one. A sound, removed from its original context (a condition referred to as 'schizophonia' by another composer some years later) can only be achieved through the use of technology. The condition had already been commonly experienced through the use of telephones and radio, but as Teruggi recounts, Schaeffer's looping of sounds led to a new experience. Famously, while listening to bell sounds on record, the stylus hit a closed groove: 'To Schaeffer's great surprise what he perceived was not a bell, but an oboe-like sound, which resulted from the absence of the attack.' (Teruggi 2007: 213) In an instant, Schaeffer had essentially uncovered two concepts. He had succeeded in objectifying the sound, that is, the bell was no longer a bell, it was no longer a recording of a bell; it was an entirely new entity. Secondly, Schaeffer had discovered reduced listening.

Michel Chion describes reduced listening as 'listening for the purpose of focusing on the qualities of the sound itself (e.g. pitch, timbre) independent of its source or meaning' (Chion 1994:223). In the case of the closed-groove bell, a happy accident of technology allowed Schaeffer to discover this quite simply. Not only were there no attack transients to signify the source, but also 'the loop was continuous, with no audible clicks' (Teruggi 2007: 213). We can imagine how much of a revelation this sudden loop must have been for Schaeffer. 
Reduced listening and the sonic object are two cornerstones of musique concrète.

Experimentation with technology is a third. While many changes would take place at RTF over the years, these cornerstones have had a lasting impression on electroacoustic music. Teruggi:

Even if the operational rules disappeared quite early in the history of GRM and of musique concrète, their influence has continued through time as an important reference thus generating a kind of universal rule: do not forget that a sound, before signifying something, is a sound, and has to be mainly considered as that. This idea permits any sound to be considered as a possible sound for music. We should always look for the sound 'itself'! (Teruggi 2007: 215)

The removal of a sound's original context and then listening to it as a new entity was a very particular way of creating and responding to new music. While it was a revolutionary idea at the time, were doors being closed to forms of expression that lay in the realm of referential listening? Certainly this is true of musique concrète in the 1950s and much of the 1960s, although the success of such works to defy their origins would be debated. 
'Listening' is a concept fundamental to acousmatic music and Schaeffer spent considerable time dissecting the listening process. In 1966, he published his ideas in Traité des Objets Musicaux, a document which set the philosophical tone of much acousmatic composition for the remainder of the twentieth-century and into the new millennium.

Denis Smalley concisely presents Schaeffer's 4 listening modes as discussed in Traité des Objets Musicaux, in his paper The Listening Imagination: Listening in the Electroacoustic Era.

The first listening mode is information-gathering. Put simply, it is not the sound we hear, but the message it carries. It is a very primitive response to the cause of sound and 'is a question ultimately of survival.' (Smalley 1996: 79)

The second mode of listening is referred to as passive reception. The idea is that one cannot help but hear a sound, perhaps for its sudden arrival or other unusual qualities. Smalley suggests such sounds might include an explosion, a ghetto blaster, a human cry, and while the passive nature of their reception can also be applied to mode one, 'the main difference is that while mode two focuses on subjective impact (my reaction to the sound), mode one concentrates on the object of my attentions (the occurrences outside me)'. Smalley notes that mode two 'is 
less satisfactory as a separate mode, and is certainly not self-contained.' (Smalley 1996: 79)

The third mode of listening represents the undertaking of appreciating and responding to attributes of sounds. This process ignores the context and messages of sounds and focusses on their 'spectromorphological'qualities. ' 'It is a selective process, where some sounds are preferred at the expense of others.' Smalley notes that these preferences depend on the listener, but in the case of a composer, 'this listening experience could ultimately lead to pertinent values being abstracted, providing the first steps in the construction of a musical code.' (Smalley 1996: 79)

The fourth mode of listening involves responding to a musical language 'as opposed to the sounds of everyday life'. This refers to the organisation of sounds within a musical syntax, or in other words, mode four is a response to the composer's placing of sounds over time.

The important thing to note here is that modes 1 and 2 are deemed unsuitable for responding to a musical language by virtue of the fact that they are made up of everyday, untransformed sounds. This is, of course, an obvious point to make, but it is the clearest indication yet that referential material still had no place at the GRM in 1966. Smalley observes that mode 3, like mode 4, is 'concerned with music listening'. The possibility that one might listen to the sounds of everyday life

8 Smalley, Denis. 'Spectro-morphology and structuring processes', in S. Emmerson (ed.) The Language of Electroacoustic Music, London: Macmillan, 1986 pp.61-93 
in the manner of 'appreciating and responding to the attributes of sound' is not accounted for, or put another way, reduced listening is considered, for the most part, something reserved for sound selection and completed musical works. Smalley himself would amalgamate his own ideas with Schaeffer's to provide an extended look at these modes, something I will discuss later.

It was generally understood that sounds were to be decontextualised, and then reconstructed in a musical language in order to create a successful piece. Schaeffer clearly deals with the issue of referentiality when discussing materials for musique concrète:

Any sound phenomena can be considered (as well as the words of language) through its relative signification or through its own substance. As long as signification is predominant, and that we play on it, we have literature and not music. But how can one possibly forget signification, isolate the 'itself' of a musical phenomena? Two previous actions must be undertaken: Distinguish an element (listen to it by itself, for its texture, its matter, its colour). Repeat it. Repeat twice the same sound fragment: there is no more an event, there is music! (Schaeffer in Terrugi, 2007: 213) 
Many composers were attracted to RTF in the early 1950's including Stockhausen, Messiaen, and Varèse amoung others. In 1958, after a period of absence, Schaeffer regained control of the studio at RTF from Pierre Henry, believing the studio had strayed off course under his direction. Schaeffer created Groupe de Recherches Musicales (GRM), invited a new batch of composers to the studio (including Luc Ferrari and Francois Bayle), and set about refining his works and methodology.

One particular participant, Pierre Boulez, having realised Étude II there in 1951, would later write of his disapproval of musique concrète in Relevés d'apprenti. Essentially, Boulez believed that musique concrète had failed to establish an artificial sound universe, which he believed should have been the primary focus of the GRMC. He also felt that the works were poorly realised in a technical sense, and that 'an agreeable nonchalance made the concrete-music studio a flea market of sounds; the bric-a-brac, alas revealed no hidden treasures.' (Boulez 1968: 290). He certainly preferred the electronic works coming out of Milan and Cologne, potentially because of the more traditional compositional approach and the preference for new (synthesised) sounds over 'found sound.'

Musique concrète, in its early years, had established itself as one of two main streams of electroacoustic music and its founder, Pierre Schaeffer, had invented two new concepts: reduced listening and the sonic object. His views put him and his followers at odds with the more traditional composers and ideals of Western art 
music, notably those who championed abstract musical language over the experimental practices at GRM.

By 1966, musique concrète had generated 15 years worth of material. Electronic music had spread across the world, synthesisers had become more advanced and numerous, there was more advanced multi-headed tape machines and multichannel mixing consoles with very complex routing capabilities. Technology had evolved at a rapid pace. Producers of popular music were exploiting the use of this technology, and many of the experimentations of the RTF were being expanded upon in this format. Recording devices had become smaller and of very high quality (developed mostly for the film industry), and individuals were already experimenting with these outside the studio. By the late 1960's, with so many developments in technology and the proliferation of electronic music globally, people may have been justified in questioning the ideals of musique concrète when contemplating its role in the future of music.

Despite this, the legacy of musique concrète has played a major role in my own music. Firstly, the practice of technological experimentation as a means to generate ideas and materials is very much a part of my work. My preferences for analogue equipment and hands-on manipulation are informed by musique concrète's early experiments with technology. Like Schaeffer, I consider myself an engineer as well as a composer, and quality electronics (especially of the 1950s, 1960s and 1970s) 
inspire me much more than the latest software. I also believe that the concepts of reduced listening and the sonic object have influenced my approach the sonic environment. I have a preference for ambiguous material, and in many instances, this encourages a state of reduced listening; a state not often associated with works of this nature.

Perhaps another aspect of musique concrète that has informed my work is that it was unable to achieve all its goals (although this doesn't make it any less valid). Just because reduced listening was the prescribed mode of listening did not mean everyone listened in that way. Schaeffer tried to make new sounds out of old ones, and while many felt he had managed this, others (including Boulez and Schaeffer himself) felt he had not. While reduced listening is a very useful and rewarding listening state, there is no guarantee that a listener will have these skills, or employ them when a composer requires. 


\begin{abstract}
Almost Nothing
If Boulez was horrified by the lack of direction, compositional technique and the penchant for 'flea market' sounds, his claim that musique concrète's 'role is of no importance' would have been further enforced upon hearing Luc Ferrari's Presque Rein No. 1 le lever du jour au bord de la mer (1970). The piece, made from a fourhour, single-point recording out a hotel window in a small Yugoslavian village, was condensed into a 21-minute work, and was his second foray into what he termed 'anecdotal' music. The first piece was Heterozygote (1964), which utilised field recordings as a material among others, but Presque Rien No.l was his first to use a field recording as the sole material. In a 1998 interview with Dan Warburton, Ferrari recounts the response of his contemporaries at GRM:
\end{abstract}

It was badly received by my GRM colleagues, who said it wasn't music! (Laughs) I remember the session where I played it to them in the studio, and their faces turned to stone... I was quite happy, because I thought it wasn't bad at all. ${ }^{9}$

Presumably, Ferrari's GRM colleagues were at odds with the obvious reference to the real world. There was no sound object, reduced listening or vigorous

9 Ferrari in Warburton 1998. http://www.paristransatlantic.com/magazine/interviews/ferrari.html, accessed 19 December 2008 
manipulation of technology. This piece was concerned with referentiality, narrative and, perhaps most importantly, it encouraged the audience to listen in a way that hadn't yet been addressed in electronic music. Presque Rien No. 1 could not be listened to in a purely reduced manner as prescribed by Schaeffer. Ferrari: "Once I'd done Presque Rien $N^{\circ} 1$ I didn't need to be that radical anymore. There's one landscape, a given time, and the radical thing is precisely that it's just one place at one specific time, daybreak". (Ferrari in Warburton, 1998)

While Ferrari, in his characteristically flippant style, had moved on, the influence of this work was far-reaching. As he recounts to Warburton, listeners in the USA were more receptive to his work. Having interviewed Ferrari in 1970, KPFA-FM, situated in Berkeley California, began programming The World Ear Project in response to his work. From 1971, The World Ear Project played hundreds of tapes sent in by composers and amateurs alike, from all over the globe. As Brandon La Belle suggests, with the proliferation of microphones and portable tape recorders, Ferrari's anecdotal work inherently 'suggest[s] that such machines may (and should) find their way into the hands of daily routine well outside the elite haven of specialized studios.' (La Belle 2006: 32). KPFA-FM encouraged just that, and within a year of Presque Rien No.l's release, the first series of The World Ear Project was broadcast, with overwhelming worldwide response. California in the early 1970s was perhaps the ideal time and place for the nurturing and expansion of a new 'radical' sound art. Attractive to the popular ideals of the time, field recording could be practiced by anyone outside the traditional art institutions, and Ferrari 
may well have been held in high regard for helping to establish this. It is difficult to say exactly how the recordings presented on the World Ear Project were 'listened to'. While the GRM did not think kindly of Ferrari's anecdotal pieces, the KPFA FM audience was presumably a lot more diverse in their listening attitudes, and much greater in number. It would be fair to say that outside the restrictive environment of the GRM, referential works were being enjoyed, by a strong percentage of listeners, for their referential qualities.

The World Ear Project could be considered the birth of phonography, although as the recording dates of many submissions suggest, people had been making private recordings since the early sixties. In fact, the Swiss-designed Nagra I was first produced in 1951 for use in radio, so there are no doubt examples of recordings from this time. In 1962, the popular Nagra III was released and used extensively in sound recording for film. Ferrari owned one and recounts in interview with Bridgette Robindore that he 'spent a year with a Nagra on [his] shoulder.' ${ }^{10}$ This was 1964, and he had amassed a large number of recordings as part of a film crew travelling across Europe.

Ferrari is a figure of great importance to me. He was the first to present the sonic environment as recorded art along the lines of photography. His ideology was not weighed down by the concerns of the studios he was emerging from. In fact, his

10 Brigitte Robindore and Luc Ferrari. 'Luc Ferrari: Interview with an Intimate Iconoclast', Computer Music Journal Vol. 22, no. 3, 1998 pp. 11 
comments suggest his anecdotal works were designed, in part, to buck the trend. Presque Rien No.1 sounds as fresh to my ears as the first time I heard it. The recording, selection of materials and their placement seems to be done with a great deal of care, and the quality of the sound is rich. For someone who works with field recordings on a regular basis, it strikes me that this work was very thoughtfully prepared. Presque Rien No.1 will be remembered as a pioneering work, but I wonder if it would have been so popular (or even released) if others hadn't recognised these qualities.

Most importantly to me, Ferrari's work does not require anything from his audience. It does not require listeners to disregard the origins of the recording, nor does it require the audience to participate in a kind of social or ecological awareness (as was the case in a developing scene in Vancouver). After many years, and many releases (initially by Deutsche Grammophon in 1970, and most recently in 2009 by INA GRM), Presque Rien No.1's only true political statement is simply this: any recorded sound can be regarded as art. 


\section{The World Soundscape Project}

For the first time, the sonic environment had been given a name. R. Murray

Schafer, a Canadian composer, taught at Simon Fraser University between 1965

and 1975. Early in his tenure he coined the term 'soundscape'. Derived from the word 'landscape' it 'consists of events heard not objects seen' (Schafer 1977: 8).

Although he was a composer, Schafer's relationship with the sonic environment did not revolve around music. Soundscape was not a material for composition; it was a material for research with a strong ecological dimension. At this basic level, Schafer's ideas differed greatly from the growing number of phonographers worldwide. In an address at the Canadian Centre for Architecture in Montreal in 2005, Schafer discussed the proliferation of phonography in the early 1970s. He was surprised that such works (including his own) were being considered as art, and insists that he and his colleagues at Simon Fraser University 'never tried to do anything like that, we simply tried to collect information'. ${ }^{11}$

It was at SFU that he founded the World Soundscape Project. Along with Bruce Davis, Peter Huse and Barry Truax (among others) Schafer set about recording, documenting and analysing the sounds of Vancouver, resulting in the publication The Vancouver Soundscape in 1973, which included a double LP of the recordings, and an accompanying booklet detailing their activities. Following a nation-wide

11 Schafer, R. Murray. Presentation at The Canadian Centre for Architecture, Montreal, May 2005. Pod-cast accessed at http://www.blesser.net/SP_downloads.html, accessed 7 May 2009. 
field-recording trip by Peter Huse and Bruce Davis, The Soundscapes of Canada aired on CBC as an hour-long, 10-part programme in 1974.

The World Soundscape Project (WSP) was established as an educational and research group by R. Murray Schafer at Simon Fraser University during the late 1960s and early 1970s. It grew out of Schafer's initial attempt to draw attention to the sonic environment through a course in noise pollution, as well as from his personal distaste for the more raucous aspects of Vancouver's rapidly changing soundscape. ${ }^{12}$

The idea of 'noise pollution' was really at the heart of the movement; according to Schafer the 'signal to noise ratio' was rendering much of the world 'Lo-Fi,' and a holistic, multi-discipline approach was needed in order to combat this problem. Schafer would leave SFU (and Vancouver) in 1975 for a more 'Hi-Fi' sound environment, and it was in this new rural setting that he penned The Tuning of the World (1977), a book which delivers an account of acoustic environments from time immemorial through to the Industrial Revolution (considered a pivotal development by Schafer and Russolo alike) and on to present day (1977). The book prescribes vocabulary, notation and classifications to deal with the acoustic environment.

12 Truax, Barry. Information sourced at http://www.sfu.ca/ truax/wsp.html, accessed 7 May 2009. 
The activities at Simon Fraser University in the late 1960s and early 1970s are fascinating to say the least. It is prudent to note that the work they did towards raising awareness of noise pollution and community-valued acoustic features and their protection was pioneering and revolutionary. Noise pollution is now considered a very real pollution, and many nations have adopted strict measures in order to keep noise levels to a minimum, protecting workers from damaging their hearing, as well as keeping residential areas free from excessively noisy cars, stereos, and airplanes. The Department of Environment, Food and Rural Affairs (UK) have generated a series of nationwide 'noise maps' intended as public health information. Here we have a good example of how noise pollution is currently being addressed at a central government level. ${ }^{13}$ As Schaefer noted in his 2005 lecture, a recent national survey conducted in Japan asking participants which sounds in the community were considered pleasant, resulted in many of these sounds becoming protected by local government. Through the ongoing work of original WSP members, their students and a growing community of concerned individuals, the World Forum for Acoustic Ecology was born in 1993. It has a large number of affiliated organisations all over the world, and it produced a journal, Soundscape: The Journal of Acoustic Ecology, bi-annually, from April 2000.

The World Soundscape Project documented their research in a very empirical fashion. Decibel readers accompanied field-recording trips, dates and times were

13 Information sourced at http://services.defra.gov.uk/wps/portal/noise, accessed 10 August 2009. 
recorded, the results mapped out in graphs. The basic premise for the research was somewhat less dispassionate. In fact, the whole exercise revolved around a highly subjective notion; that some sounds are better than others. This issue was not lost on Schafer:

Sorting sounds according to their aesthetic qualities is probably the hardest of all types of classification. Sounds effect individuals differently and a single sound will often stimulate such a wide assortment of reactions that the researcher can easily become confused or dispirited. As a result, study of this problem has been thought too subjective to yield meaningful results. Out in the real world, however, aesthetic decisions of great importance for the changing soundscape are constantly being made. (Schafer 1977: 146)

The fundamental concern, that 'aesthetic decisions' were being made arbitrarily (or perhaps cynically in the case of muzak and advertising), was a key concern to Schafer. He essentially felt that his role was to raise awareness about the soundscape through study, and ultimately to render the results of these studies into law, protecting some sounds, and diminishing others. Regardless of the somewhat biased position of Schafer, he did make some very useful classifications for addressing the acoustic environment. Many of these terms made their first 
appearance in Schafer's book The Tuning of the World, first published in 1977. I have found these to be helpful in understanding the effects of certain sound environments on those hearing them. To a great extent, these terms have influenced my understanding of the sonic environment, and in turn, my use of them in composition. I will discuss this with regard to my work later.

'Keynote is a musical term; it is the note that identifies the key or tonality of a particular composition.' (Schafer 1977: 9) Schafer means this as a metaphor, except in the cases of electricity $(50-60 \mathrm{~Hz})$ and perhaps the combined low frequency hum of tyres on roads and huge air conditioning ducts found in cities. His examples of keynotes include the cobbled streets of Zurich, and the wooden sidewalks of British Columbia, ('stone' and 'wood' being their respective keynotes). The sound of the sea, rivers, wildlife, etc are also included. Essentially, sounds you don't notice until they are absent make up 'keynote' sounds. For this reason, Schafer suggests that these sounds have a subtle effect on the mood of individuals and communities, going as far as to suggest that keynote sounds affect our folklore and presumably other forms of cultural expression. (Schafer 1977: 9)

'Signals are foreground sounds, and they are listened to consciously.' Schaefer gives the examples of train whistles, telephones, church bells and warning devices. This is a somewhat unsatisfactory category, as there are many different types of 
foreground sounds 'listened to consciously' but Schafer's examples seem limited to those that are man-made with encoded messages.

'The term Soundmark is derived from landmark, and refers to a community sound which is unique or possesses qualities which make it specially regarded or noticed by people in that community.' This is an interesting category, and probably the most subjective of all. As we will see, Schafer was not unaware of this issue. 


\section{Soundscape as Composition}

Another term that Schafer coined (one we have already encountered) was 'schizophonia'. Literally, the term derives from the Greek words 'schizo' (to split), and 'phone,' (voice or sound). The concept describes a sound split from its original context, and reproduced as an electroacoustic soundscape. This 'nervous' word, as Francisco Lopez correctly points out, describes the same principle as another composer's concept: '[S]chizophonia and objet sonore are antagonistic conceptions of the same fact.' (Lopez 1997) This 'schizophonic' condition was a condition Pierre Schaeffer revelled in, and R. Murray Schafer obviously did not:

Sounds have been torn from their natural sockets and given an amplified and independent existence. Vocal sound, for instance, is no longer tied to a hole in the head but is free to issue from anywhere in the landscape. (Schafer 1977: 90)

This echoes Kircher's fascination with such a prospect, but it was not a welcome experience by everyone 300 years later. Schafer for example, a man obviously fascinated by the sonic world around him, did not share the same desire to harness and manipulate sound as did Russolo, Ruttmann, Cage and Ferrari had before him. Schafer viewed the soundscape as its own entity. Capturing sounds and replaying them through loudspeakers had no merit outside of analysis and education, and for 
the most part, such practice would simply add to the global noise floor. It is interesting to note that it was Schafer's colleagues and students who began experimenting with the idea of 'soundscape composition,' that is, viewing these environmental recordings in a musical light while retaining a degree of educational purpose. On the one hand, this is hardly surprising as the majority of WSP participants were in fact composers. They had no doubt heard of Luc Ferrari's work and were probably aware of KPFA's World Ear Project also. The connection between the World Soundscape Project and Luc Ferrari's work has never been made explicit, perhaps, in part because of their vastly different ideologies. Ferrari:

R.M. Schafer came to GRM around that time [late 1960's], but I never actually met him. Yet I have always been chagrined by the fact that he has never acknowledged me. Take Presque Rien, ou le lever du jour au bord de la mer. In this composition, very little, almost nothing, takes place. It is a soundscape work, only I never gave it this name, nor did I need to create a theory about my approach. The work is a series of sequences that represents a natural, given situation captured by a given manner of recording. This was the most radical composition I had ever composed. I was asking myself the question of how a composer can unfold this type of piece specifically without any musical sounds. My intuition allowed me to arrive at this solution. At the time, Presque Rien was known throughout the world, as Deutsche 
Grammophon released it. Perhaps I have not been cited because my work was not scientific or expressive of a researchers attitude. I have no pretensions of being the sole instigator of environmental recordings. I do not claim to be an inventor either, but I know that I am a pioneer. (Ferrari in Robindore, 1998: 13)

Ferrari reveals a great deal about himself in this paragraph, as well as a number of important distinctions between his work and Schafer's. Firstly, Ferrari refers to Presque Rien as 'composed' and conceived with intuition. Along with the statement that his work was 'radical' it is clear to see that Ferrari considers his work to fit within the realm of musique concrète - or at the cutting edge of it - even if his colleagues did not. While Ferrari does not resonate with Schafer's theories or 'scientific' approach, he obviously considers himself an influence, at the very least on the soundscape composers who followed. Schafer on the other hand, without acknowledging Ferrari, considers himself a pioneer of such work, citing The Vancouver Soundscape LP as the first instance of environmental recording being regarded as art, kicking off a movement in Europe. He makes this clear at the Canadian Centre for Architecture in 2005, while discussing the response to The Vancouver Soundscape:

A lot of these recorded soundscapes began to be [laughing] regarded as art. And it started actually in Germany with quite a 
famous German producer, radio producer, by the name of Claus

Scherning, at the West German Radio in Cologne. He played the whole of the Vancouver Soundscape recording as if it were a new kind of composition, a musical composition that we'd put together, and he got so excited about it that he then commissioned more city portraits, by composers in London, New York, Venice, Berlin, San Francisco, Lisbon and Barcelona. (Schafer 2005)

Yet as we have seen, works of this nature had already impacted on Europe and America before his project. Walter Ruttmann had created a portrait of Berlin more than 40 years prior to The Vancouver Soundscape LP. Europe had already heard minimally edited 'environmental' works three years earlier with Presque Rien No 1, and The World Ear Project had gathered and presented pieces from all over the world in the wake of Ferrari's work. Schafer continues:

I think we stimulated a lot of that activity, um, very much with the recordings that we did. However, my purpose and our purpose, was not to make works of art, but to simply provide ourselves with a catalogue of information, sound information that we could measure. (Schafer 2005) 
Schafer clearly shows distain for field recordings as art, which is very much more obvious when listening to the pod cast in its entirety. He also reiterates that his purpose, and the purpose of the WSP was to document, purely for scientific purposes. It would become very obvious that Schafer was not speaking on behalf of all at WSP.

'During the production in 1974 of a ten-part radio series for the CBC called Soundscapes of Canada, a significant change occurred in the use of recorded material, in this case derived from a cross-Canada recording tour in 1973.' Barry Truax notes that while there were some collectively authored works similar to those found on the entire Vancouver Soundscape recordings, there had been a substantial shift to individual authorship. 'In several cases, the radio documentary format was used, although with more sound examples than the conventional approach. However, in other cases, more extensive transformation was used with the sounds and their composition, such as Bruce Davis's Work and Games, Barry Truax's Soundscape Study and Maritime Sound Diary, and Howard Broomfield's A Radio Program About Radio Programs, all composed in 1974.' (Truax 2002: 5)

It would seem that 1974 was a particularly big year for field recordings on the airwaves. KPFA FM was airing the fourth season of The World Ear Project, CBC was running the Soundscapes of Canada, and West German Radio was playing The Vancouver Soundscape and commissioning new works globally. For soundscape 
composers, the ideas encapsulated in the World Soundscape Project were still very much at the heart of their work. Unlike Ferrari, who arrived at anecdotal music as a way to be radical, rebelling against l'objet sonore and the traditional European notion of the composer, soundscape composers were fully focused on the ecological and social messages contained in their works. This can be seen in the writings and practices of soundscape composer Barry Truax, a man very much at the heart of the WSP, and a composer who continues to explore the possibilities of environmental material in electroacoustic composition decades after the events at SFU.

While there are many works I find interesting under the banner of soundscape and acoustic ecology, I find some of the ideas to be at odds with my own work. R. Murray Schafer represents an interesting set of values, and is a curious leader of the movement. He is obviously fascinated by the soundscape like so many before him, and yet he holds no desire to capture and represent them in a musical light. The recording and replaying of sounds, outside of educational purpose, is discussed with some degree of negativity. To Schafer, recorded soundscape as art is laughable, and yet, so many of his followers began making art of this kind.

More than anything, Schafer drew attention to the sonic environment and developed a quasi-scientific way to categorise it. This has been most helpful in the battle against noise-pollution. In terms of my own work, Schafer's research has 
encouraged me to consider the environment in his terms: keynotes, signals and soundmarks. His work has also encouraged me to think of how others might respond to these sounds. Unlike Schafer, I don't presume to know how others will respond, but I acknowledge that many of his perspectives on the subject are valuable. 


\section{Soundscape Composition}

The term 'soundscape' has become so widespread that it has prompted R. Murray Schafer to announce, somewhat wryly, that he "should have copywritted [sic] the word.” (Schafer 2005) 'Soundscape', in the world of film and game music refers to sound design or 'ambient' music. It is also the general tendency to describe any work that utilises environmental recordings as 'soundscape composition,' a term which some composers find loaded and restricting. Francisco Lopez, a composer who uses environmental recordings exclusively in his compositions places his work squarely in the musique concrète camp. He sees the acoustic ecologists'

preoccupation with environmental context as an attack on personal expression. He concludes his essay entitled 'Schizophonia vs l'objet sonore: soundscapes and artistic freedom' with this request:

'Schaferians: please, let us Schaefferians to have the freedom of a painter.' (Lopez 1997)

Perhaps this situation has arisen in part because of the large number of composers who align their work with ecology and documentary concepts of sound-based art. For the purposes of definition, I will explore some of the concepts presented by Barry Truax and other soundscape composers (Darren Copeland and Claude Schryder). 
Truax provides four basic types of soundscape compositions, which are reprinted here:

1) Listener recognisability of the source material is maintained, even if it subsequently undergoes transformation;

2) The listener's knowledge of the environmental and psychological context of the soundscape material is invoked and encouraged to complete the network of meanings ascribed to the music;

3) The composer's knowledge of the environmental and psychological context of the soundscape material is allowed to influence the shape of the composition at every level, and ultimately the composition is inseparable from some or all of those aspects of reality;

4) The work enhances our understanding of the world, and its influence carries over into everyday perceptual habits (Truax in Drever 2002: 22)

The relationship between the composer and the listener is explicit. With the notable exception of classification 3, the focus is very much on the listener's response to the work, and that the composer is responsible for informing that response. In the case of the third classification, the composer realises the 'environmental and psychological context' in the work, presumably if not for the listener's sake, then at the very least for the composer's. What is explicit here is the focus on context. The spectromorphological and spatial aspects of the recordings are secondary to the 
messages they carry and thus do not tally with the notion of reduced listening. Truax makes this point clear:

The soundscape composition cannot be defined as any piece using soundscape recordings as its source materials, mainly because contemporary signal processing techniques can easily render such sounds unrecognisable and completely abstract i.e. with few if any real-world referents. The soundscape composition always keeps a clear degree of recognisability in its sounds, even if some of them are in fact heavily processed, in order that the listener's recognition of and association with these sounds may be invoked. Or, to put it even more simply, it is always clear what the soundscape composition is 'about' (Truax 2002: 6)

Much like Schaeffer's focus on sonic objects and reduced listening, Truax's insistence on not only retaining the original context of the materials, but to also impart a narrative or meaning to a listener seems restrictive from a creative pointof-view. This is obviously a concern to Francisco Lopez. 


\section{Soundscape Composition versus Musique Concrète?}

As Bob Gluck points out in his writing The Nature and Practice of Soundscape

Composition (1999), many soundscape composers are quick to distance themselves from the ideas of musique concrète. To highlight this point, Gluck references

Truax:

The essential difference between an electroacoustic composition

[i.e. acousmatic and abstract] that uses pre recorded

environmental sound as its source material, and a work that can

be called a soundscape composition, is that in the former, the

sound loses all or most of its environmental context. (Truax in

Gluck 1999: 16)

Copeland and Schryer re-emphasise this point, with Copeland providing a commentary on abstraction:

Abstraction is merely just one available working method among a host of others... [within] an artistic medium which can engage a new heightened realm of listening sensitivity, a mode of listening that can facilitate intellectual engagement with the meanings and 
messages embedded in the sounds of daily life...Abstraction closes doors on the worlds located within experiential world. (Copeland in Gluck, 1999: 19)

It could also be said of soundscape composition that a fixation on the referential closes doors on worlds located within the abstract, which is of course, the point of Lopez' contention. His compositions, while drawing on the sounds of the world for material are to be listened to in an abstract manner. He is 'Schaefferian' by his own confession, and has stated that:

There can only be a documentary or communicative reason to keep the cause-object relationship in the work with soundscapes, never an artistic / musical one. Actually, I am convinced that the more this relationship is kept, the less musical the work will be. (Lopez 1997)

Lopez' comments are interesting, as he squarely aligns himself with R. Murray Schafer, despite not concurring with the majority of his ideas. Essentially, Schaeffer, Schafer and Lopez all agree that unprocessed field recordings in acousmatic work is inherently 'unmusical'. As we have seen, Pierre Schaeffer would eventually dismiss his own endeavours as unmusical as well. Through the likes of Lopez, it would seem Schaeffer's original concepts have outlasted his own 
belief in them. The major rift in ideology occurs between Schafer and his followers. When Lopez implored Schaferians for freedom, R. Murray Schafer himself would probably have joined in.

I myself agree with Lopez in many respects, though not all. Like him, I believe that composers have the right to use field recordings in any way they see fit, without having to communicate meaning in the manner of soundscape composition. For this reason alone, I feel my work, though using materials closely identified with the soundscape movement, is conceptually very different.

I do not agree with Lopez's assertion that pieces with a retained cause/object relationship are 'less musical'. This is very much a Schaefferian concept, and I see it as problematic. I believe the relationship between cause and object is informed by a third factor, that is listener experience. Boulez's experience with recorded sound led him to believe that Schaeffer's concrete pieces were simply 'a flea market of sounds'. Ironically, I find many of the materials used in Truax's 'soundscape' pieces unrecognisable, while Lopez's materials are at times identifiable. This is not always the case, but it illustrates my point. Regardles, I do not believe that if a listener can identify a cause/object relationship then a work is less 'artistic'. 


\section{Tensions}

By way of summary, the legacy of musique concrète, notably the focus on the sonic object and reduced listening, allows little room for the appreciation of environmental 'anecdotal' works such as Ferrari's Presque Rien series. Such works are usually consigned to the realm of 'soundscape composition,' a movement typified by the retention of the cause/object relationship, a focus on acoustic ecology, and a clear intention/reception relationship between audience and composer.

What, then, of works that utilise field recordings that are neither designed to be listened to in a purely reduced manner, or as representational of 'real' environments? Can Schaeffer's listening mode 3 (a form of reduced listening) be applied to sound environments that are unprocessed? Does not the experience of a listener dictate what is referential in many cases? Does not the recording of a sound environment render it a sound object by mere definition? Do they then, as Lopez suggests, need to be further abstracted in order to become musical? What kinds of discourse need to be present in order to consider a work 'musical'?

These questions point to two key factors, namely the role of the composer, and the role of the listener. 


\section{The Composer}

In dealing with compositions that utilise field recordings, it is important to make clear observations about phonographic works and electroacoustic ones. For the purposes of definition, Ferrari's Presque Rien No 1 is a phonographic work. It is minimally edited, the original recording is preserved as much as possible, and the composer intends that you hear the content as referential. The role of the composer exists primarily in the framing of materials and the selection of recording and playback media. A comparison can be drawn to photography, where certain objects are framed, focused and developed in a manner determined by the photographer. As we will see, this does not mean that phonography sits outside of electroacoustic composition, but rather it represents an extreme end of the compositional spectrum.

Many of the questions surrounding the role of the composer of electroacoustic music stem from traditional ideas of how composers make music. Boulez, Stockhausen and Cage, all giant figures of twentieth-century art music, favoured, at various times of their careers, what Simon Emmerson refers to as 'abstract syntax' (Emmerson 1986: 20). This is where a pre-determined formula decided upon by the composer is used to control the materials of the piece. Such is the case with more traditional forms of music (sonata form and serialism to name two), but also in the case where the syntax is decided on by chance or third-party codes, as was the case with much of Cage's work. Emmerson has suggested a 'grid' of possible discourse 
and syntax types, within which composers often traverse freely. These include varying levels of 'aural' and 'mimetic' discourse. Mimetic refers to 'the imitation not only of nature, but also aspects of human culture not usually associated directly with musical material.' Aural material is denoted as 'abstract musical substance.' (Emmerson 1986: 19). In the case of electroacoustic music, a sound abstracted beyond recognition is an example of aural material and a recognisable environmental recording is an example of mimetic material.

As we have seen, the activities at the Cologne Studios in the 1950's rested heavily at one side of Emmerson's grid. That is to say many works created there, notably Stockhausen's Electronic Studies (1953 and 1954), utilised aural discourse with abstract syntax. Synthesisers were used to generate new sounds, with serial techniques predetermining their relationships to one another and placement over time. While Pierre Schaeffer and the GRMC attempted to create aural discourse with sound objects, Boulez believed they failed at this, thus spawning his comments to this effect in Notes of an Apprentice.

The musical material, if it is to lend itself to composition, must be sufficiently malleable, susceptible to transformations, capable of giving birth to a dialectic and supporting it... nothing, absolutely nothing, resulted from that almost incoherent method [musique concrete]. (Boulez 1968) 
While Schaeffer and Boulez were obviously at odds with each other over the practices at RTF, they did share an understanding that referentiality got in the way of music. Schaeffer was trying to address this, Boulez felt he was failing.

Ferrari's Presque Rien works would be used to describe the other side of Emmerson's grid: that of mimetic discourse with abstracted syntax. This same description could be used for much soundscape composition, as Emmerson makes clear:

The composer may preserve the relationships of the soundobjects made in an environmental recording, for example in the Ferrari works already referred to, thus abstracting his syntax from them. Deliberately abstract forms and relationships may, however, be created as the basis of the montage, as in Stockhausen's Telemusik. Or the reconstructed image may be manipulated into unexpected juxta- and super-positions not usually encountered in the real world, creating surreal dreamscapes or dialectical oppositions, thus superimposing a 'story line' upon the material, and mediating between these two extremes. (Emmerson 1986: 23) 
I consider this to be the most clear and useful statement of how compositions with environmental materials relate to the world of electroacoustic composition. It shows at once how their materials and composition exist at the very opposite end to more traditional forms of music, especially those championed at the outset of electroacoustic composition, thus providing one reason why such works haven't been easily received. Mimetic discourse with abstracted syntax is the starting point for many of my own works. Some pieces do not stray very far from this end of the continuum, while others explore more abstract materials in a more directed fashion. As a composer of environmental sounds, it is refreshing to find a theoretical framework that encompasses the materials and processes I use without the baggage of 'acousmatic' music.

It is also noteworthy that listener response is not accounted for in Emmerson's appraisal. Emmerson emphasises the mechanics and techniques of making music and not its reception. The exclusion of listener response from his analysis is important, as it essentially opens the door to all forms of response. The response of a listener is key to the appreciation of works with environmental recordings, as I will soon discuss. Emmerson also provides the single strongest argument validating phonographic works in the realm of electroacoustic music. He makes a very common analogy to make a very simple point: 
The photograph is a good parallel in that it is so clearly not the original object itself, the act of 'recording' becoming part of the new artifact. The will of the composer, far from abdicated, is crucial. (Emmerson1986: 38)

Where the likes of Schaeffer and Boulez, seemingly dismiss unprocessed field recordings as being unfit for electroacoustic composition, Emmerson allows for their presence on his grid of musical discourse. Like Ferrari's anecdotal works, phonography utilises mimetic material in an abstracted discourse. If there is any distinction to be made between a purely phonographic work and an electroacoustic work, it is that the latter has the freedom to move around Emmerson's grid, while the former locks itself in place.

Phonography is practiced more widely than ever before. The Internet is largely responsible for this, providing forums, social networking sites and file sharing hubs for sound-recordists to post their work, discuss technology, and interact with each other. Myspace.com has more than 100 million members worldwide. Users can post their music (whatever that may be) for others to listen to for free. More specific sites relating to sound art, such as freesound.org have tens of thousands of users. These users post their recordings on the site for members to download for use under a Creative Commons license. These files frequently involve recordings 
that could be classed as phonographic. Yitzchak Dumiel writing at the dedicated site for phonographers (phonography.org) ${ }^{14}$, describes the practice:

Auditory events are selected, framed by duration and method of capture, and presented in a particular format and context, all of which distinguishes a recording from the original event during which it was captured. (Dumiel)

Dumiel clearly denotes the difference between a soundscape and its recording, reflecting Emmerson's comment. He distinguishes phonography from other forms of recording, as the emphasis is placed on the recording of a sonic event and not production of it afterwards. 'This bias reflects an attempt to discover rather than invent.' (Dumiel)

14 Phonography.org is host to more than 50 artists, providing biographies, recordings, essays and links to other sites pertaining to the practice and methodology. Information sourced at http://www.phonography.org/whatis.htm, accessed 7 December 2008 


\section{Listening}

Audience reception, it would seem, is an area where many composers endeavour to impose their will. With both musique concrète and soundscape composition, the role of the audience is fundamental to the success of a piece. As we have seen, Barry Truax has made this point explicit when discussing soundscape composition. The way in which the audience receives musique concrète was also made clear by Schaeffer. Musique concrète requires a listener to cognitively bracket sounds and focus on them for their intrinsic qualities and formal discourse. In other words, the audience should listen (as the composer does) in a reduced manner, focussing on the interplay of sonic objects.

In my opinion, reduced listening asks a lot of a listener. Boulez suggests that early practitioners of musique concrète failed in providing works that could be listened to in such a manner. Reduced listening is essentially a learned experience. As the human ear naturally looks for codes and messages in sounds, as a matter of 'survival', it would seem that reduced listening requires that the listener acquire a new cognitive ability, much as traditional musical abilities are acquired.

In the case of Boulez, and in fact many composers familiar with the recording and manipulation of sound, his experience with technology allows him to unpack the 
abstract and make real again. Smalley calls this 'technological listening' ${ }^{15}$ and as Schaeffer would have us ignore a sound's origin, Smalley would have us ignore its manipulation. Recently, Leigh Landy recounted how a piece of his for tape and flute was performed in New York, where Trevor Wishart attended. Wishart told Landy he did not like the work, because he spent the whole concert trying to identify how it was achieved in a technical sense. ${ }^{16}$ It could be said that the most 'educated' ears for electroacoustic music are also the most tainted. Technological context, that is the identification of technology's role in sound production, is a fundamental concern of acousmatic composers, and is therefore difficult to extract from their listening experience. I would also suggest that those unfamiliar with sound production are aware of technological context, for the most part on a subconscious level, although with the proliferation of cheap electronic music products, the number of people using sound technology, and therefore the appreciation of technology's role, is rising. Recently, hip-hop artist Jay-Z released a song untitled D.O.A (Death of Auto-Tune) which suggests that his audience are aware of (and perhaps tired of) this effect. It has been a dominant vocal effect in popular music since Cher's 1998 release 'Believe,' especially in American 'urban' pop. The proliferation of guitar pedals have had the same effect on large audiences, as modulation, signal degradation, dynamic, spatial and filtering effects have been available to consumers since the 1960 s.

15 Smalley, Denis. 'Spectromorphology: Explaining Sound-Shapes', Organised Sound Vol. 2, no. 2, 1997 pp. $108-109$

16 Landy, Leigh. Presentation at the New Zealand Electronic Music Symposium, Auckland University, 2 September 2009. 
Additionally, the synthesisers used in early electronic music pieces, instruments considered to be generators of the most abstract sounds at the time, are simply not the big secret they once were. Technology is now widely available, and what were once tools reserved for electroacoustic composition are now, thanks in part to their use in Hollywood sci-fi, the tools of everyday music making. This is certainly true in the case of dance music. For example, 'Acid House' audiences recognise the sound of a Roland TB-303 bass synthesiser as a crucial element of the genre. Where Stockhausen may have heard a high tone violently twisting from tension to rhythmic stability, a modern dubstep producer hears a hand reducing the rate on a ring-modulator. Technology's ability to generate 'abstract' material only lasts so long and human ears, formally educated or not, uncover the codes faster than ever before. The possibility that reduced listening is redundant in our current climate is not the focus of this essay, but it is easy to see that our ability to experience music in such a way is confounded by the proliferation of technology, and our everwidening experience of sound. In short, as time passes, musique concrète encounters more and more difficulty maintaining the desired relationship with its audience. As the ability for sound objects to remain entirely self-referential diminishes, the effectiveness of Schaeffer's listening modes to remain relevant to the genre diminishes also.

Soundscape composition has other difficulties. In a genre where the successful transferal of an idea from composer to listener is vital, making that connection in our modern world seems a lot harder than it may have been in the 1970s. R. 
Murray Schafer acknowledged the problem surrounding differing responses in the community when discussing soundmarks:

Now, one of the problems of course with soundmarks, is that it depends on a constant population with constant attitudes because if the population changes what might be a soundmark, a very affectionately regarded sound for some people, might become unpleasant for people of a different generation. (Schafer 2005)

Constant attitudes in our increasingly globalised community seem less and less possible. The ability for a composer to share a message through the use of referential material (without the aid of supporting literature) almost seems an impossible task, though the intention/reception model is still considered by many to be a defining feature of works with environmental material, Lopez being the obvious exception.

Smalley describes a condition he refers to as transcontextuality, in which a dual experience occurs when listening to acousmatic music where the source of the sound is recognised by the listener, even as the listener is conscious of the fact that it is part of a piece of acousmatic music: 
Where the sounds taken from cultural activity or nature are used as recorded, or where transformation does not destroy the identity of the original context, the listener may become involved in a process of transcontextual interpretation.' (Smalley 1996: 99)

The condition above describes the relationship as existing between the listener and the material. Such a relationship seems likely, and potentially very rewarding, as the listener at once engages with the work as well as their own experience of life. Smalley takes it a step further:

In transcontexts the composer intends that the listener should be aware of the dual meanings of a source. The first meaning derives from the original, natural or cultural context of the event; the second meaning derives from the new, musical context of the composer. (Smalley 1996: 99)

While a diverse relationship between referential material and the listener seems inevitable to me, a relationship between the composer and the listener seems a much less achievable goal. Such a relationship is dominant in soundscape composition, but is this the case of all work with referential material? Lopez believes a transcontextual relationship, especially ones traditionally preferred by 
soundscape composers, is unnecessary. He believes environmental matter has the 'full right to be self-referential, not being subjected to pragmatic goals such as a supposed, unjustified re-integration of the listener with the environment'. (Lopez 1997)

In works where mimetic discourse is dominant, though the composer's intention is not a key feature (rather a true exploration of the material on the part of the listener is encouraged), traditional modes of listening as presented by musique concrète and soundscape composition do seem to be particularly appropriate. Where works move between aural and mimetic materials, where technology processes these materials to varying levels of recognition, and where the listener's experience of the piece is valued as much as the composer's, a mode of listening is required where these values are addressed. 


\section{Indicative Relationships}

The most useful model I have found for listening to works with varying levels of environmental sound and referentiality comes from Denis Smalley. I have already alluded to his work in this essay and it is here that I will discuss it in some detail. Smalley's work successfully encompasses the ideas of Schaeffer, while allowing for the listening experiences better suited to referential works and soundscape composition. Smalley achieves this by placing value on experiences contained within Schaeffer's first and second listening modes. Where Schaeffer had seen these as basic human responses to sound (and therefore unsuitable for musical discourse within electroacoustic music), Smalley sees these experiences as part of a greater, more complex listening network. Essentially, Pierre Schaeffer created a listening model suitable for a new form of music that was responding to a particular set of historical and aesthetic conditions (those of the post-war avantgarde). Denis Smalley has done the same for the contemporary era, which reflects a different and perhaps more culturally open-ended context. His listening modes are summarised as follows:

1) Indicative Relationship

2) Reflexive Relationship

3) Interactive Relationship 
In short, an indicative relationship is a mode of listening where messages are the focus (much like Schaeffer's mode 1). Smalley notes that this field 'has been created to explain the links between human experience and the listener's apprehension of sounding materials in musical contexts'. (Smalley1996: 83) A reflexive relationship is where the affect of the sound on the listener (the subject) is the focus, and finally, an interactive relationship is where the listener is 'continuously exploring the qualities and structure of the object' in an interactive fashion. Smalley notes that the interactive relationship includes Schaeffer's reduced listening, although 'no pre-formed expectation is sought by the listener'. Perhaps most importantly, the interactive relationship 'embraces aesthetic attitudes towards music and sounds'. (Smalley 1996: 82) It is here we find an inclusive attitude that allows referential listening to sit alongside reduced listening with equal consideration. Smalley's interactive relationship is sensitive to different kinds of compositions and their respective audiences. Furthermore, Smalley expresses that 'as far as Western art music is concerned there should ideally be a partnership between the reflexive and interactive'. (Smalley 1996: 82)

Perhaps Russolo and Cage experienced a 'reflexive relationship' when listening to the world, though it is more likely that a constantly changing listening perspective is the reality, informed by their very unique experiences of life. Perceptual shift and life experience is a key theme in Smalley's work. As mentioned, his indicative relationship is not relegated to the world of basic human function, and he encourages a different approach. He suggests a more meaningful experience of 
referential material can be had when it is listened to as more than information about objects.

Indicative relationships, while forming a major aspect of our use of the auditory sense, are largely regarded as a trivial and inferior attitude to sounds when it comes to considering the sounding materials of the art of music, where interactive relationships are considered psychologically more rewarding. However, if we do not confine the notion of the indicative relationship to mere messages, events and information, but extend it to include a wider frame of references to experiences outside and beyond music, we immediately penetrate both more extensively and deeply into the relationship between musical experience and our experience of living. (Smalley 1996: 82-83)

Here, Smalley clearly acknowledges the negative attitudes towards referential material in acousmatic composition, while making a case for a more integrated experience of music with lived experience. In fact, he offers a view that seems to somewhat devalue the idea of reduced listening and sound objects while extending an open hand to a more open and audience-integrated listening experience: 
The sounding materials within a composition cannot be solely or even primarily self-referential. The apprehension of musical content and structure is linked to the world of experience outside the composition, not only to the wider context of auditory experience, but also to non-sounding experience. Approached from the multiple perspectives of life outside music, the materials and structure of a musical composition become the meeting place of sounding and non-sounding experience. (Smalley 1996: 83)

This is perhaps the clearest articulation of how I perceive my own music and its relationship to a person who hears it. It is truly a meeting place of expression and experience. Like Schafer, Smalley has created an analysis of 'indicative' sounds that I have found to be greatly beneficial when approaching field recording and making pieces from such recordings.

His indicative relationships include:

1) Gesture (the physical movements of a human acting sounding objects)

2) Utterance (sounds linked directly to the human body)

3) Behaviour (how sounds interact with each other)

4) Energy and Motion (spectromorphological properties of sounds) 
5) Object/substance (the 'material' nature of sounds)

6) Environment (incorporation of the sound environment into music)

7) Vision (associative synaesthesia)

8) Space (the use of space to articulate sounds)

Smalley notes that these fields are not mutually exclusive, referring to them as 'networks.' Space, for example is required to inform each of the other fields and so on. While the environment field deals directly with the sound environment, each of these fields can be found within any given sound environment, and therefore Smalley provides tools, which could be used to describe a musical environment (the attributes of an acousmatic piece), and a sonic environment (the world around us).

Smalley's ideas, like Emmerson's, allow for pieces with solely or partially referential materials to exist easily alongside more abstract works. Further to this, he allows for the flow of referential material and abstract materials within a single work. He suggests that all listening experiences are valid when approaching electroacoustic music, and that the ability for acousmatic composition to explore these relationships is a unique feature of the genre. A listener can identify the indicative nature of a sound, without having to disregard its origin. Listener recognition and 're-intergration' with source material (as Lopez puts it) is not required, although if this is the composer's intention and the listener is willing, 
such a transaction has a home in Smalley's interactive listening model. Smalley allows for listeners to experience sounds and discourse without the heavy ideologies that have historically plagued compositions with referential materials. He does however acknowledge that in preserving referentiality, some kind of duality exists between the composer and the audience. The nature of this duality is somewhat hard to define, and in my view it depends greatly on the experience of the listener and the intentions of the composer. Further to this, where referential material is recognised, there is no guarantee that a listener will 'get the message' and no guarantee that a composer is in fact sending one.

As shown, soundscape composition is greatly concerned with transcontextual interpretation. It could also be argued that any piece that has recognisable material will encounter such an interpretation whether the composer intends this or not. In the case of soundscape composition, the source of the sound should be identifiable to a greater or lesser extent, and the listener, required to 'complete the network of meanings,' hears the message of the composer. Smalley notes that 'successful transcontextual interpretation is dependent on shared norms and meanings.' This is certainly the case where language is involved, and very much in line with the comments of Schafer regarding community response. Smalley acknowledges that 'the decoding of transcontextual meanings can be a very personal and fragile affair.' (Smalley 1996: 100) 


\section{A Personal and Fragile Affair}

One could argue that a transcontextual relationship between composer and listener, where specific meaning is transmitted and received, is an impossible exercise. I myself find the concept to be somewhat meaningless. My own experience of music as a listener is so deeply personal that I feel any attempt to convey meaning through sound can only exist at a superficial level. How can a composer presume to know how a listener will respond to sounds and their arrangement in a piece? There are of course, many cases where certain sounds have similar connotations across different cultures (through his research, Schafer identified the pleasing sound of a cat purring being one of them).${ }^{17}$ However, when considering the multitude of experiences a human can have and the multitude of contexts (cultural or otherwise) in which these are had, it is truly fruitless to assume individuals will respond to sounds in the same way. The lapping of waves on the shore may evoke a sense of inner-peace and memories of summer at the beach for one person, but a feeling of sadness, memories of love lost, or drowning for another.

Perhaps the only certainty regarding the reception of referential material is that clearly recognisable sounds will evoke a more personal response in a listener: unease, nostalgia, excitement etc. Less discernible material will engage a listener in a more exploratory process. For listeners more accustomed to the world of

17 Schafer, R. Murray. Presentation at The Canadian Centre for Architecture, Montreal, May 2005. Pod-cast accessed at http://www.blesser.net/SP_downloads.html, accessed 7 May 2009. 
acousmatic music, some material may induce an experience of reduced listening, or encourage an appreciation of the formal discourse, while more inexperienced ears may appreciate the feelings the materials create, while constructing their own personal narrative. Much research has been done in this area, most notably Leigh Landy and Robert Weale's intention/reception project. ${ }^{18}$ Many of the results show that experienced listeners and inexperienced listeners have very different reactions to works with environmental materials.

In terms of my own work, the transcontextual experience as outlined by Smalley is muted in favour of a direct relationship between listener and materials. In the case of phonographic works, a simple mediation takes place to enable this in an uncomplicated fashion. With larger scale works, where mediation is more pronounced, a duality inevitably occurs, where the listener experiences the formal discourse of the composition, and the references contained in the material. My pieces do not presume a set of responses from the audience. The pieces are composed in such a way that listeners are encouraged to interact freely with the materials. In the case of Nightwork (a piece that uses materials collected at a refugee village in Guatemala), some listeners may focus on the words spoken at the Mayan ceremony (should they speak the same hybrid language), others will listen closely to the characteristics of the individual speaking (age, gender) with perhaps fascination at hearing a language for the first time. Some may be drawn to the sounds of technical manipulation (technical listening); others may be trying to

18 Weale, Robert. www.aural-initiative.com/thesis.pdf, accessed 3 March 2009. 
gather a sense of space in a chaotic environment. All listeners will without doubt converge at the sudden sound of a mortar being fired (as is the nature of humans), and the aftermath (an insect cacophony) will allow some listeners to experience reduced listening, while others may reflect on the similarities of such wildlife with other places in South America. This is a short, hypothetical list of responses to the materials in Nightwork, though such a list could be endless. My role in Nightwork, possibly the most referential of my pieces, is to guide the audience through the listening experience, encouraging at times more meditative states of listening, and at others, urgent, directed states. In this regard, there is a strong sense of narrative in this piece, though it is not the composer's intention to ascribe meaning to the narrative. The listeners, as seen with the hypothetical list of responses above, are encouraged to do this themselves. I believe that Nightwork, as Smalley puts it, is first and foremost a 'meeting place of sounding and non-sounding experience'.

As with much music with abstracted syntax, the materials are often left to interact in their original form. This is the case with Chikatetsu, where the opening of the piece involves a raw recording of the San Francisco subway. The sound objects in the recording are very dynamic and seem almost faked, though no additional editing and manipulation is used to create the effect. While the juxtaposition of materials thereafter is more of an abstract syntax (i.e., the will of the composer is governing), they are presented in a way that is sympathetic to the movement and content of the original material. In the case of Chikatetsu, pitch elements are extracted, as the initial activity naturally fades to inactivity, and these pitches 
develop from background noise to foreground activity, mirroring the opening's dynamic envelope at a slower speed. Attention to form is very important to my pieces. Again, this is derived from the materials used. The compositional process, therefore, is very intuitive. It requires a very intimate knowledge of the materials and the inevitable integration of technology into the pieces must be addressed. The layering of sound worlds can at times create confusion and tension, and at others stunning clarity of environments that are yet alien. Tension, stasis, harmonic content, rhythmic content, timbral content and at times melodic content must all be dealt with in a manner suitable to the spectromorphological and spatial characteristics of the material, and as such my pieces can at times be crude and lively (as is the case with Nightwork), or subtle and expansive (Woljeong-sa is an example). However, the spatial integrity of the original recordings is often preserved, as this reflects my belief that spatial awareness provides the strongest connection between humans and their environment, mostly as complex reflections indicate that an environment is 'real' and unique. Smalley's work on space-form in acousmatic music certainly argues such a case, and Smalley articulates this understanding via the work of French sociologist Henri Lefebvre:

space is'...neither a mere 'frame', after the fashion of the frame of a painting, nor a form or container of a virtually neutral kind, designed simply to receive whatever is poured into it. Space is a social morphology: it is to lived experience what form itself is to 
the living organism, and just as intimately bound up with function and structure. (Smalley 2007: 38)

It is difficult to provide an overarching guide to how I deal with materials, because the materials themselves are always the governing factor; a point I have tried to make explicit above and which is well articulated by Smalley:

My understanding of what I hear is not just a matter of hearing but of my knowledge of being able to act in the soundscape, being physically able to be in it... Similarly, an acousmatic musical work has the potential to harness my enactment, my spatial enactment. (Smalley 2007: 40)

On reflection, the primary goal of my research has been to find a place for my own compositions in the world of electroacoustic music. While there is much discourse surrounding the use of referential material in electroacoustic music, my work still seems to move between the various ideologies without a clear home in any one camp.

The exciting potential of everyday sound as a material for music, as expressed by Russolo and Cage at the dawn of electroacoustic music, is very much at the heart of my work. While many others have obviously felt this same excitement, heavy 
ideologies have, in my opinion, plagued the use of these materials, forcing compositions into categories that don't necessarily reflect their true nature. I have certainly felt this with my own compositions. I identify strongly with Luc Ferrari who clearly felt the need to break from these restrictions and embrace the technology and the sound environment fully. I also identify with Lopez, who finds the ideologies of soundscape composition, a genre with which he is often identified with, as being restrictive and not reflective of his work.

The notion of reduced listening has influenced my work greatly, and in many respects my work stems from the tradition of musique concrète. As we have already heard, Pierre Schaeffer notes 'the dissociation of seeing and hearing ... encourages another way of listening' (Schaeffer 2006), and it is with these ears that I approach the sonic environment. Perhaps my association with musique concrète is better viewed through the work of Lopez. He feels that environmental material in his work should be heard as 'self-referential', even though the source may be recognised. It is certainly true that I choose materials primarily for their sonic properties over their referential qualities, though I prefer the freedom to move between the abstract and the referential as a part of the formal structure of my work. Perhaps one of the strongest ties between my work and musique concrète is the emphasis on experimentation with technology. I find both the unlimited potential of environmental sound and the unlimited potential of audio technology to be sources of great inspiration to me, and the combination of these two potentials is the true genesis of all my pieces. 
Schaffer's keynotes, soundmarks and signals, along with his general observations and passion, have encouraged me to listen to the sonic environment critically, and have proven great tools for decoding the soundscape. The world of soundscape composition has less influence on my work, primarily because the emphasis of composers to communicate meaning through material to listeners does not reflect my own ideals. My hope is that a listener hears my work in the context of electroacoustic composition. Any dual context experienced by the listener arising from the recognition of sounds or their arrangement is essentially a relationship between the materials themselves and the listener's experience of life. In my work, listeners are encouraged to interact with the compositions as they see fit. My role as composer is not to provide a commentary to be inferred through the work, but rather to provide material with which an audience can build their own 'network of meanings'.

Where my work truly finds support is with the ideas of Emmerson and Smalley. Emmerson's grid, a compositional framework for electroacoustic materials and language, clearly encompasses the use of referential materials, abstract materials and anything in between, allowing for both pre-composed forms and 'abstracted' forms. Likewise, Smalley's indicative and interactive listening modes allow my works to be heard as they are intended; where referential materials help facilitate audience interaction. Phonographic pieces, works that have traditionally been at home on radio (and now with increasing internet support), also find home with Smalley, Emmerson and the world of electroacoustic composition. 
Finally, while I do not believe programme notes to be of much value to a listener, especially in light of my attitude towards transcontextuality, I have included them below in order to provide some insight into the way the pieces were composed. Phonographic works are simply titled as a time and place, with no further detail. As much as I hope these notes will help, I believe that a more rewarding experience will be had if my works are listened to in a quiet room through a nice sound system without them. 


\section{Programme Notes - Compact Disk 1}

Track 1 Woljeong-sa (2009)

Woljeong-sa explores materials collected at a snow-covered mountain temple in the Gangwon Province of South Korea shortly after dusk. The recordings are manipulated and arranged in an improvised fashion, using an analogue mixing console and outboard hardware effects, including digital processors and tape machines. Woljeong-sa is a meeting place for un-processed field recordings, highly processed materials and the sounds of the technology used.

Track 2 Chikatetsu (2009)

Chikatetsu incorporates recordings collected in the San Francisco Subway (B.A.R.T) and the Yamanote Line train in Tokyo. Both recordings contain diverse pitch material, the dominant pitches are extrapolated and developed to form the central section of this piece.

Track 39.49 pm, 10 October 2006, Acapulco, Mexico.

Track 4 Gatun Lock (2009) 
This piece explores a range of materials, most of which were collected aboard the SS. Topaz at the entrance to the Panama Canal. The sonic environment at the Gatun Lock is characterised by the sounds of water, rail, cargo ships, whistles and bells, all of which feature strongly in this work.

Track 5 Үеоји (2009)

The recordings for Yeoju were made in South Korea in a seemingly rural community. Each day between $5 \mathrm{pm}$ and $7 \mathrm{pm}$, an ominous roar would emanate from the hills. I later discovered this to be the sound of an 8-lane expressway located a few kilometers away, completely out of sight. Yeoju uses recordings of this environment, along with a local temple bell, to reveal a barren and mysterious environment. 


\section{Programme Notes - Compact Disk 2}

Track 1 Koen (2009)

Koen, the Japanese word meaning 'park' (as in a public garden), features recordings made in various parks across Japan at different times of the year. The calls of Tokyo's ever-present winter crows and the wind-up summer insects of Minakami reflect off the huge concrete pavements and towering trees. Whether at the expansive grounds of the renowned Meiji Koen, or at a local Buddhist temple in the countryside, humans and nature collide in a manner that is unique to Japan; the sonic environments equally as distinct.

Track 2 11.23pm, 12 June 2007, Uehara, Tokyo, Japan.

Track 3 8.25am, 13 June 2007, Uehara, Tokyo, Japan. 


\section{Track 4 Ruahine (2009)}

Ruahine explores materials collected at Te Apiti Wind Farm located at the southern end of the Ruahine ranges over looking the small town of Ashhurst. The massive blades of the turbines make an almost calming rhythm as they cut through the air. They are at their most dramatic when not moving at all - the silence of towering sentinels in wait - humbled only by the mass of the ranges they stand on. The recordings were made in a variety of wind conditions, with the more inventive recording techniques saved for the unstoppable nor-westerly.

Track 5 5.13pm, 19 November 2007, Yoyogi, Tokyo, Japan.

Track 6 Nightwork (2009)

This piece uses recordings made at a small refugee village in the mountains north of Antigua, Guatemala. The inhabitants, thrust together at the end of a long and tragic civil war, combine their differing customs and languages in order to build a future together. The sonic environment of this human interaction is charged and 
chaotic at times, matched somewhat by the wildlife that takes over once the village sleeps. 


\section{Bibliography}

Adorno, Theodor W.

The Curves of the Needle. In Essays on Music (1927). (Susan H. Gillespie et al., Trans.).

Berkeley: University of California Press, 2002.

Bacon, Francis.

New Atlantis (1624). http://www.gutenberg.org/dirs/2/4/3/2434/2434-h/2434-h.htm, accessed 9 August 2009

Benjamin, Walter.

The Work of Art in the Age of Mechanical Reproduction (1936)

http://www.marxists.org/reference/subject/philosophy/works/ge/benjamin.htm, accessed 23

June 2007

Boulez, Pierre.

Notes of an Apprenticeship, trans by Herbert Weinstock. New York: Knopf 1968

Brindle, Reginald Smith.

The New Music: The Avant-Garde Since 1945 (second edition). Oxford and New York: Oxford University Press, 1987 
Busoni, Ferruccio.

Sketch of a New Esthetic of Music (1911).

http://www.archive.org/details/sketchofanewesth000125mbp, accessed 19 January 2009

Cage, John.

The Future of Music: Credo (1937), in Cage, Silence; Lectures and Writings, Connecticut: Wesleyan University Press, 1961

Chion, Michel.

Audio Vision: Sound on Screen, trans. Claudia Gorbman, New York: Columbia University

Press, 1994

Drever, John.

'Soundscape composition: the convergence of ethnography and acousmatic music'. Organised Sound Vol.7 no. 1, 2002 pp.21-27

Dumiel, Yitzchak.

'What is Phonography?', http://www.phonography.org/whatis.htm, accessed 7 December 2008

Emmerson. Simon.

'The Relation of Language to Materials', in S. Emmerson (ed.) The Language of

Electroacoustic Music, London: Macmillan, 1986 pp 17-39 
Ferrari, Luc and Warburton, Dan.

Interview conducted 22 July 1998.

http://www.paristransatlantic.com/magazine/interviews/ferrari.html, accessed 19 December 2008

Ferrari, Luc and Robindore, Brigitte.

'Luc Ferrari: Interview with an Intimate Iconoclast', Computer Music Journal Vol. 22, no. 3, 1998 pp. 8-16

Glinsky, Albert.

Theremin: Ether Music and Espionage. Chicago: University of Illinois, 2000

Hodgkinson, Tim.

'Pierre Schaeffer an interview with the pioneer of musique concrete'. Interview conducted 2

April 1986. http://www.ele-mental.org/ele_ment/said\&did/schaeffer_interview.html, accessed 7 June 2009

King, Michael.

The Penguin History of New Zealand. Auckland: Penguin Books (NZ), 2003.

La Belle, Brandon.

Background Noise: Perspectives on Sonic Art. London: Continuum International Publishing Group Ltd, 2006.

Landy, Leigh. 
Presentation at the New Zealand Electronic Music Symposium, Auckland University, 2 September 2009.

Lopez, Francisco.

'Schizophonia vs l'objet sonore: soundscapes and artistic freedom' January, 1997.

http://www.franciscolopez.net/schizo.html, accessed 7 June 2008

Norman, Katherine.

'Hard Cash (and small dreams of change)', in Sonic Circuits V, American Composers' Forum (Innova 114), 1999.

Russolo, Luigi.

The Art of Noises (1913). http://120years.net/machines/futurist/art_of_noise.html, accessed 19 January 2007

Ruttmann, Walter.

http://www.medienkunstnetz.de/works/weekend-remix/, accessed 8 April 2009

Schaeffer, Pierre.

'Acousmatics', in Christoph Cox and Daniel Warner (ed.) Audio Culture, New York: Continuum Publishing Group Inc. 2006 pp 76-81

Schafer, R Murray. 
The soundscape: our sonic environment and the tuning of the world. New York: Knopf, 1977.

Schafer, R. Murray.

Presentation at The Canadian Centre for Architecture, Montreal, May 2005. Pod-cast accessed at http://www.blesser.net/SP_downloads.html, accessed 7 May 2009.

Smalley, Denis.

'The Listening Imagination: Listening in the Electroacoustic Era', Contemporary Music Review, Vol. 13, Part 2, 1996, pp. 77-107

Smalley, Denis.

'Spectro-morphology and structuring processes', in S. Emmerson (ed.) The Language of Electroacoustic Music, London: Macmillan, 1986 pp. 61-93

Smalley, Denis.

'Space-form and the acoustic image' Organised Sound Vol. 12 no. 1, 2007 pp. 35-58

Smalley, Denis.

'Spectromorphology: Explaining Sound-Shapes', Organised Sound Vol. 2, no. 2, 1997 pp.

$107-126$

Teruggi, Daniel. 
'Technology and musique concrete: the technical developments of the Group de Recherches Musicales and their implication in musical composition'. Organised Sound, Vol. 12 no. 3, 2007 pp. $213-231$

Truax, Barry.

'The World Soundscape Project', http://www.sfu.ca/ truax/wsp.html, accessed 7 May 2009.

Truax, Barry.

'Genres and techniques of soundscape composition as developed at Simon Fraser University'. Organised Sound, Vol. 7, no. 1, 2002 pp. 5-14

Varèse, Edgard.

http://www.thereminvox.com/article/view/7/1/1/, accessed 8 April 2009

Weale, Robert.

'The Intention/Reception Project: Investigating the relationship between composer intention and listener response'. www.aural-initiative.com/thesis.pdf, accessed 3 March 2009 